\title{
PROCESSO DE IMPLANTAÇÃO DA POLÍTICA NACIONAL DE HUMANIZAÇÃO EM HOSPITAL GERAL PÚBLICO
}

\author{
DEPLOYING THE NATIONAL HUMANIZATION POLICY AT A GENERAL PUBLIC HOSPITAL \\ PROCESO DE IMPLANTACIÓN DE LA POLÍTICA NACIONAL DE HUMANIZACIÓN EN UN \\ HOSPITAL GENERAL PÚBLICO
}

\author{
Alessandra Barbosa Pereira ${ }^{1}$ \\ João Leite Ferreira Neto ${ }^{2}$
}

Resumo O artigo analisa a experiência de implantação da Política Nacional de Humanização em uma instituição hospitalar pública de Belo Horizonte, Minas Gerais. Focalizam-se os avanços e limites da gestão participativa proposta pela política de humanização no cenário hospitalar. Trata-se de uma abordagem qualitativa, por meio de um estudo de caso no qual se utilizam pesquisa documental, entrevistas e observação. Os dados foram tratados mediante a análise temática de conteúdo, construindo-se categorias temáticas numa perspectiva da história do processo de implantação da Política Nacional de Humanização. O esforço da fase de implantação e o apoio do Ministério da Saúde não se sustentaram a médio prazo no hospital. A Política Nacional de Humanização apresenta inovação em relação às práticas do setor privado, ao superar um modelo de humanização centrado na 'satisfação do cliente', associando as práticas de cuidado às de gestão. Contudo, o maior desafio é transpor essa lógica e instaurar uma nova forma de se relacionar e atuar na saúde. Para que isso ocorra, é necessário intervir sobre a totalidade da conjuntura institucional. Palavras-chave política de saúde; Política Nacional de Humanização; processo de trabalho; gestão participativa.
Abstract This article analyzes the experience of deploying the National Humanization Policy at a public hospital in Belo Horizonte, state of Minas Gerais, Brazil. The focus is on the progress made and on the limitations of the participatory management proposed by the humanization policy in the hospital setting. It is a qualitative approach based on a case study that uses documentary research, interviews, and observation. Data were treated by means of thematic content analyses, building theme categories from the perspective of the history of the process of deploying the $\mathrm{Na}$ tional Humanization Policy. Neither the efforts made during the deployment phase or the support provided by the Ministry of Health were sustained over the medium term at the hospital. The National Humanization Policy represents an innovation in relation to private sector practices by overcoming a humanization model focused on 'customer satisfaction,' associating care and management practices. However, the biggest challenge is implementing this logic and introducing a new way to relate to and act on health. Action is needed on the institutional panorama as a whole in order for this to occur.

Keywords health policy; National Humanization Policy; work process; participatory management. 


\section{Introdução}

Este trabalho visou analisar uma experiência de implantação da Política Nacional de Humanização (PNH) em uma instituição hospitalar pública de Belo Horizonte, capital do estado de Minas Gerais. Buscou-se, ainda, conhecer elementos da gênese dessa política, também denominada HumanizaSUS, analisar os efeitos da PNH na relação entre o hospital e o Ministério da Saúde e identificar pontos conflitivos e dissonantes entre a discursividade da política e as práticas concretas. Dentro do escopo deste artigo, privilegiou-se a análise dos avanços e limites da gestão participativa proposta pela PNH no cenário institucional hierarquizado e marcado pela 'urgência' do cotidiano do trabalho hospitalar.

O tema da humanização na saúde não é recente. Está em pauta desde 1960 com as reivindicações do movimento feminista, tendo ganhado fôlego e notoriedade a partir da década de 1990 com as ações, projetos e programas que foram definindo o campo da humanização na atualidade. Esses projetos e programas, porém, estavam demarcados por um fracionamento de áreas, identificando-se com algumas profissões ou focando no cliente e na qualificação hospitalar (Benevides e Passos, 2005).

Uma conjunção de fatores proporcionou um cenário favorável para a emergência da temática da humanização e sua inserção na agenda política. A reivindicação da sociedade expressa na XI Conferência Nacional de Saúde, cujo tema foi "Efetivando o SUS: acesso, qualidade e humanização na atenção à saúde com controle social" (Brasil, 2003b), reuniu-se à demanda institucional de uma política transversal possibilitada pela nova gestão do Ministério da Saúde, que, há muito, debatia os temas sistematizados no texto da PNH.

O HumanizaSUS, instituído em 2003, apresenta-se como uma aposta na mudança das práticas e na valorização de processos sociais e subjetivos, ou seja, sustenta-se em tecnologias relacionais para produzir saúde. Partindo do entendimento de que novos modos de pensar, perceber, sentir e fazer na saúde não se consolidam sem posicionar a subjetividade em lugar de destaque (Deslandes, 2005), o HumanizaSUS reconhece a centralidade dos processos de subjetivação de todos os atores envolvidos na produção de saúde (usuários, trabalhadores e gestores) para a modificação de práticas, culturas e sujeitos (Brasil, 2009) e, com isso, possibilitar a efetivação do projeto assistencial do Sistema Único de Saúde (SUS).

\section{O percurso metodológico}

A estratégia metodológica empregada na investigação que deu origem a este artigo, o qual é fruto de dissertação de mestrado que contou com o financia- 
mento do Conselho Nacional de Desenvolvimento Científico e Tecnológico (CNPq), está ancorada na abordagem qualitativa por meio de um estudo de caso, o que permite a utilização de várias técnicas de produção de dados (pesquisa documental, entrevistas, observação etc.), de acordo com o delineamento do estudo.

A implantação da PNH em uma instituição de saúde foi o caso escolhido. O critério de escolha do serviço onde ocorreu a investigação partiu da premissa de que era indispensável que o equipamento de saúde tivesse a PNH em fase avançada de implantação e que o serviço se situasse em Belo Horizonte, por causa dos custos menores e da facilidade de acesso. Assim, foi escolhido um hospital geral de caráter público, considerado pelo Ministério da Saúde referência nacional na implantação do HumanizaSUS.

Após a aprovação da pesquisa pelo Comitê de Ética da instituição estudada, resguardando a resolução n. 196/1996 do Conselho Nacional de Saúde, foram realizadas cinco entrevistas semiestruturadas com pessoas que poderiam contribuir significativamente com dados acerca da constituição do HumanizaSUS e sua implantação no hospital em questão. Foram entrevistados duas gestoras da instituição pesquisada que participaram ativamente do processo de implantação da $\mathrm{PNH}$; um trabalhador da Secretaria Municipal de Saúde de Belo Horizonte que teve importante participação nessa implantação; e dois consultores do Ministério da Saúde e do HumanizaSUS, sendo um deles integrante do grupo formulador da $\mathrm{PNH}$.

Na sequência, iniciou-se a pesquisa no hospital, realizada de março a dezembro de 2010. O período de observação variou conforme a demanda do trabalho de campo: ora trabalhou-se durante vários dias consecutivos, ora em torno de duas vezes na semana, com uma duração média de uma e três horas cada visita. Nessa fase, utilizaram-se fontes documentais. Os documentos do Ministério da Saúde que se relacionavam com a PNH foram acessados por meio das publicações disponíveis na internet. Já a acessibilidade aos documentos internos do hospital dependeu da disponibilização e da seleção da instituição, o que demandou negociações e busca de parcerias. Houve, porém, escasso êxito nesse empreendimento e pouquíssimo material foi disponibilizado, ficando inacessível a grande maioria dos documentos internos da instituição, como relatórios, atas, registro de oficinas, planejamentos de ações, programação de cursos e capacitações, que possibilitariam uma análise mais aprofundada e detalhada do processo de implantação das diretrizes e dispositivos do HumanizaSUS. Em momento algum houve recusa formal à disponibilização de documentos, e sim apenas a protelação de respostas e viabilizações. Os documentos consultados foram publicações oficiais da instituição estudada e uma programação extraoficial com agendamentos de cursos para gestores e outra programação para trabalhadores, do ano de 2010. 
Outro recurso metodológico foi a observação com anotações sistemáticas em diário de campo. Por causa da insuficiência do tempo dispensado ao estreitamento de laços, delimitaram-se três unidades de produção (UPs) como foco principal das observações. Essas unidades foram escolhidas no sentido de contemplar tanto a assistência do pronto atendimento, por meio do acolhimento com a classificação de risco, quanto a internação hospitalar, empreendida pela clínica médica e os centros de tratamento intensivo (CTIs).

Campos e Rates definem unidade de produção como um “espaço onde o processo de trabalho é construído e desenvolvido por equipes multiprofissionais, e não mais por um agrupamento de profissionais" (Campos e Rates, 2009 , p. 47). É, portanto, um arranjo organizativo que almeja promover a integração do trabalho em saúde, favorecendo a responsabilização e os vínculos, a fim de propiciar a integralidade do cuidado por meio de equipes multidisciplinares.

Apesar de as observações terem privilegiado as três UPs mencionadas, não se restringiram a elas, pois as observações ocorreram durante todo o período do trabalho de campo e abarcaram comportamentos, ambientes, situações, informações, murais, comentários, condutas e protocolos, entre outros. Buscou-se, dessa forma, compreender a rotina do serviço, bem como a percepção dos servidores em relação ao seu cotidiano no trabalho e à PNH. Dessa maneira, todas as falas de trabalhadores provêm dessas anotações. Por causa do contexto de conversação no qual foram recolhidas, essas anotações por vezes trazem um tom de informalidade e desabafo que não é típico das entrevistas formais.

Os dados produzidos foram tratados por meio de análise temática de conteúdo (Turato, 2003). As entrevistas foram gravadas e transcritas, e as anotações do diário de campo foram organizadas em categorias temáticas com base em critérios de repetição e relevância, de modo a não menosprezar elementos minoritários dissonantes. Como o estudo teve por foco o processo de implantação da PNH no hospital, organizamos os dados analisados numa linha de tempo, separados em seções iniciadas pela formulação da política, passando pela construção da parceria em torno da gestão participativa, até chegar à experiência de implantação no cotidiano hospitalar. Portanto, uma perspectiva histórica orientou o desenvolvimento de nossa análise. Trabalhou-se, concomitantemente, a apresentação dos dados e sua análise, concordando com Pope, Ziebland e Mays que "o processo analítico começa durante a fase de coleta de dados, pois os dados já coletados são analisados e inseridos ou formatam a coleta de dados em andamento" (Pope, Ziebland e Mays, 2009, p. 79). 


\section{O processo de formulação da Política Nacional de Humanização}

A PNH é uma política pública de saúde e se insere em um conjunto maior, que são as políticas públicas sociais. O Ministério da Saúde enfatiza que a PNH como política difere de um programa, por apostar em ampla inserção transversal no sistema de saúde e não se restringir a ações pontuais (Brasil, 2008). Com isso, pretende fomentar mudanças nas práticas em saúde e nas relações que se produzem nesse campo.

Essa concepção proporciona à PNH a inserção ou a influência de seus pressupostos nos variados planejamentos de ações, projetos e programas, além das diversas políticas e instâncias do SUS, a fim de empreender sua capilarização no sistema de saúde e atingir seus objetivos de mudanças e sua consolidação.

No intuito de valorizar seu potencial instituinte, o HumanizaSUS abdicou da institucionalização por meio de portarias (Trajano, 2010), consolidando-se, inicialmente, por um documento-base e cartilhas. Se, por um lado, entendeu-se que assim seria a maneira adequada e coerente de afirmar o HumanizaSUS como uma política provocadora de novos movimentos, por outro, como é possível escapar da institucionalização quando se pretende estabelecê-lo como política pública? É preciso ponderar que, no processo de institucionalização de um movimento instituinte, há ganhos e perdas. De um lado, ganha-se em abrangência e garantia de aporte de recursos orçamentários estatais; de outro, perde-se parcialmente a potência de inventividade ante práticas mais burocratizadas (Ferreira Neto, 2011).

Em 2003, iniciou-se uma nova gestão no comando do país. Gastão Wagner de Sousa Campos, professor da Universidade de Campinas e que já havia atuado como secretário municipal de Saúde nessa cidade, assumiu como secretário executivo da Secretaria Executiva do Ministério da Saúde (Brasil, 2003a). Autor de vasta produção acadêmica e participante do movimento pela Reforma Sanitária, Gastão Campos trouxe para o Ministério da Saúde ideias, metodologias e construções intelectuais, gestadas entre a academia e os serviços de saúde, que passaram oficialmente a compor os textos de diversas 'políticas nacionais' produzidas por esse ministério. Conceitos como o de clínica ampliada, cogestão, apoio matricial, entre outros, passaram a fazer parte do vocabulário das políticas de saúde. Essas e outras noções também compuseram o arcabouço teórico do HumanizaSUS.

A avaliação inicial dessa nova gestão no Ministério da Saúde verificou que a instituição ministerial era fortemente marcada por relações verticais e por escassa comunicação, como relata o entrevistado: 
verificou-se que ele [Ministério da Saúde] era marcado por um grau de abertura comunicacional muito estreito, de tal forma, que [o ministro Humberto Costa] começa a falar da necessidade de um MUS, um Ministério Único da Saúde, exatamente porque havia dentro do ministério uma fragmentação (Consultor do Ministério da Saúde 1).

A formação desse 'ministério único' não ocorreu, mas essa noção possibilitou pensar na necessidade de estratégias para promover a integração na própria instituição, ampliando-a para os serviços de saúde.

Ainda em 2003, foram sendo construídas as bases da Política Nacional de Humanização da Atenção e da Gestão do SUS à medida que ela ia sendo experimentada. A PNH optou por integrar no texto da política experiências exitosas, com a compilação de projetos e programas humanizadores de assistência, demonstrando que novos parâmetros para a saúde são viáveis na medida em que se procura combinar a defesa da vida com a construção de novos padrões de qualidade para ela, englobando, rearticulando e potencializando suas ações, bem como "espraiando o conceito de humanização para o conjunto de práticas de saúde do SUS" (Brasil, 2003a, p. 2) e disseminando a ideia de que há um "SUS que dá certo".

Compreende-se que a afirmação pretende valorizar e ressaltar o que há de interessante, inovador, inventivo e resolutivo ocorrendo nos diversos serviços. De fato, é importante destacar e comemorar as conquistas positivas, porém, com a discursividade do que 'dá certo', arrisca-se negligenciar os vários e graves problemas da organização da atenção, das práticas assistenciais, dos interesses corporativos, da gestão autoritária, por vezes sem capacitação e competência, do sucateamento dos estabelecimentos, da formação deficitária, segmentar e direcionada ao mercado privado, e do financiamento insuficiente, entre outros.

\section{Gestão participativa e humanização}

No hospital estudado, iniciou-se em 2003 uma nova gestão que assumiu o desafio de criar novos valores e novos arranjos gerenciais pautados na democratização das relações, no compartilhamento de responsabilidades e nas pactuações coletivas.

A gestão participativa ou cogestão propõe uma mudança de paradigma gerencial e a descentralização das decisões nos diversos níveis da instituição, com a consequente abertura à participação e à democratização do poder. A PNH defende "um modo de administrar que inclui o pensar e o fazer coletivo, sendo, portanto, uma diretriz ético-política que visa democratizar as relações no campo da saúde" (Brasil, 2009, p. 10). 
Tal mudança paradigmática era o objetivo da nova direção, composta por servidores públicos do hospital implicados com a qualificação do SUS. Era um grupo experiente nos modos de gerir coletivos dialogados, negociados e participativos, o que determinou a transição do modelo de gestão e a posterior implantação da PNH. Conforme um relato, "nessa época, as relações aqui eram verticalizadas, tinha um superintendente, tinha os diretores, e as decisões eram de cima para baixo" (Gestora 2).

Campos afirma que as mudanças se operam e se efetivam em saúde na medida em que há envolvimento e implicação dos sujeitos nesse processo:

As coisas e as pessoas são duras às mudanças. Embora, é a história que nos confirma, mudanças ocorram. Aprendemos que a ocorrência de grandes transformações depende sempre de pelo menos dois elementos: do desejo, da vontade desesperada de alterar o status quo, de uma dimensão subjetiva portanto; e também do domínio de uma certa ciência, de um projeto conscientemente construído, uma vertente, inapelavelmente, vinculada ao exercício da razão (Campos, 2006, p. 30).

Atentos à interdependência entre produção de novas subjetividades e renovação cultural no referido hospital, o grupo gestor se esforçou por construir propostas e buscar soluções conjuntas com os trabalhadores e usuários, visando à solidificação de uma nova política institucional. Desse modo, a gestão colegiada tornou-se, na concepção dos gestores, uma potente estratégia para possibilitar as mudanças pretendidas. A gestão participativa ocorre quando há "maior incorporação possível de práticas de gestão pelo maior número de atores possível" (Rivera, 1996, p. 366). Nesse sentido, houve grande empenho da direção da instituição para que a proposta se efetivasse na maioria dos trabalhadores. Porém, segundo as gestoras entrevistadas, ela enfrentou grande resistência por parte deles e dos sindicatos.

Apesar de não haver consenso sobre a definição de participação, é comum o termo ser tomado como autoexplicativo. Demo (2009), ao se esforçar para delinear o conceito, afirma que "participação é conquista", denominação que batiza o livro no qual discorre sobre o tema. Ele defende o caráter de conquista por ser processual e necessitar estar sempre se renovando, constituindo-se, se inquietando. Segundo o autor, "não existe participação suficiente, nem acabada. Participação que se imagina completa, nisto mesmo começa a regredir" (Demo, 2009, p. 18).

Assim, para que o sujeito seja considerado participativo, não basta que ele esteja presente nos espaços, nas ações; deve desenvolver uma atitude compromissada, implicada, envolvida. No caso estudado, percebe-se que a resistência inicial ao modelo de gestão proposto é efeito tanto do desconhecido, da novidade que o processo de mudança pressupõe, quanto do fato de a proposta ter sido trazida pelo grupo diretivo e não ser resultado do anseio 
dos trabalhadores em promover a mudança, ocasionando, com isso, uma ausência de sentido compartilhado para o projeto e a consequente oposição em instituir um novo modelo gerencial. Não seria, assim, uma forma de impor um projeto? Demo (2009) analisa que não há planejamento ou educação leia-se, nesse caso, capacitação, mobilização e ação - que não estejam embutidos em algum nível de imposição, pois a participação não é uma tendência natural ou absolutamente espontânea, como explicitado anteriormente, ela é impulsionada, fomentada por algo que afeta os sujeitos coletivamente.

Apesar das resistências iniciais, a direção do hospital manteve o empenho em negociar e dialogar com os trabalhadores sobre a nova proposta. O grupo diretor identificou nos pressupostos da $\mathrm{PNH}$ a possibilidade de acelerar a concretização do projeto de gestão e tomou essa política como instrumento de intervenção.

Concomitantemente, o apoio do Ministério da Saúde foi incisivo na experiência de implantação da PNH no hospital em questão, pois ele tinha grande interesse em estabelecer uma referência de sucesso para impulsionar a propagação da recente política pública.

Concorda-se com Reis, Marazina e Gallo quando afirmam que "uma política de humanização efetiva só pode ser compreendida como uma verdadeira intervenção institucional na lógica instalada dentro do sistema de saúde" (Reis, Marazina e Gallo, 2004, p. 42). Nesse tocante, para que uma intervenção na modalidade proposta pela $\mathrm{PNH}$ tenha efeito de contágio ela não pode se restringir a ações de grupos isolados, departamentos específicos, equipes bem intencionadas ou gestores implicados; ela deve incluir planos diretores, planejamentos dos serviços, intervenções das equipes e acolhimento dos usuários.

A PNH trabalha com três princípios básicos associados: a inseparabilidade entre modos de gestão e de atenção; a transversalização de saberes, poderes e afetos na ação cotidiana dos serviços e das práticas de saúde; e a aposta na autonomia e protagonismo dos sujeitos (Pasche, 2009). Tais ênfases coadunam com as expectativas da gestão do hospital, o que gerou o convite para a realização da parceria.

No momento de divulgação e disseminação do HumanizaSUS, uma das estratégias adotada pelo Ministério da Saúde para a inserção dessa política nos serviços de saúde se deu por meio do mecanismo de 'apoio institucional'. Atualmente, a PNH investe na formação de tutores e apoiadores dos próprios serviços como forma de manter seu potencial instituinte e expandi-lo.

Segundo os formuladores da $\mathrm{PNH}$, o apoio institucional é tanto um método interativo renovador no "modo de se fazer coordenação, planejamento, supervisão e avaliação em saúde" (Brasil, 2008, p. 53), extrapolando formas tradicionais de gerenciamento que burocratizam, segmentam e esvaziam o trabalho de sentido e satisfação, quanto uma postura, pois implica 
favorecer experiências construtivas entre sujeitos que se relacionam, reconhecendo e valorizando os diversos conhecimentos, experiências, interesses, poderes e papeis (Passos, 2006).

A partir das mudanças que foram sendo construídas no hospital, apoiadas intensivamente pelo Ministério da Saúde, formulou-se novo dispositivo de disseminação da PNH: as visitas técnicas. Trata-se de excursões aos equipamentos de saúde compreendidos pelo Ministério da Saúde como boas práticas. O objetivo do Ministério da Saúde era que os interessados em implantar a PNH tivessem contato direto com os dispositivos em operação, escutassem o relato das pessoas que participavam do processo, suas dificuldades e desafios, e a superação deles, percebessem os impactos gerados, tirassem as dúvidas e avaliassem o funcionamento in loco, ou seja, entrassem em contato com uma experiência de sucesso do SUS. A estratégia é bem vista pelos gestores:

Uma coisa que o ministério tem usado é trazer diretores, gestores, de outros hospitais do país inteiro para nos conhecer e ver a nossa experiência. E isso, pelo relato dessas pessoas que vêm nos visitar, tem um impacto enorme (...), [elas] voltam com outro gás (...). É diferente quando você vai e vê a coisa implantada (Gestora 1).

Contudo, a visita técnica tem limitações derivadas do tempo restrito para a observação do cotidiano, de não se ter construído uma relação de proximidade e confiança com quem está na prática, a fim de se inteirar dos reais problemas, e porque a visita técnica geralmente é guiada pelos gestores ou seus representantes, visto que são eles que vão apresentando os visitantes aos trabalhadores. Isso ocasiona um conhecimento superficial e, por vezes, uma superestimação da experiência. Assim, a avaliação positiva dessa estratégia não é unanimidade: "É uma propaganda enganosa, quando o povo [das visitas técnicas] vai embora, as máscaras caem" (Técnico superior de saúde).

Todos os esforços empreendidos tanto pela instituição hospitalar quanto pelo Ministério da Saúde foram válidos para transformar a implantação da PNH nesse local em uma experiência de sucesso, considerada uma boa prática. As experiências exitosas são importantes por demonstrar na prática as saídas possíveis diante de determinado problema. Entretanto, não se pressupõe "que a experiência exitosa seja o melhor caminho para se buscar conhecimento sobre o que fazer" (Spink, 2004, p. 1), pois pode ser tomada como uma "prática melhor" e levar a "julgamentos normativos das ações que 'devem' ser seguidas por estarem 'corretas'" (Spink, 2004, p. 3), podendo se estagnar nesse lugar.

Stralen (2010) sugere que uma experiência, ao se tornar exitosa ou ser identificada assim, além do bônus inerente a essa avaliação - seja ele o 
reconhecimento ou uma premiação -, pesa sobre ela um ônus. Stralen (1995) relata a experiência pioneira do Projeto Montes Claros, identificada como uma das marcas da Reforma Sanitária que embasou a configuração do SUS. $\mathrm{O}$ autor afirma que as interessantes mudanças promovidas por esse projeto, precursor das propostas da Reforma Sanitária e que lhe renderam o título de experiência exitosa, ocorreram com imensas dificuldades, que foram se apresentando no caminho, e explicita, ainda, como os atores envolvidos se esforçaram para que o projeto não fracassasse. A narrativa do autor ilustra como uma prática, quando transformada em modelo de sucesso, acarreta complicações e problemas para os que participam da experiência concreta, pois, muitas vezes, tornam-se valorizadas e estimadas em demasia. A sustentação dessa posição se faz à custa do esforço e sacrifício de quem está na ponta dos serviços, os trabalhadores, que, por vezes, são designados a desempenhar um papel sem saberem ao certo qual é ele ou qual a sua finalidade, ou, ainda, ocultar seus reais problemas para sustentar o discurso de boa prática.

Esses ônus da sustentação do estatuto de prática exitosa se fizeram sentir em alguns momentos da pesquisa, tanto na já mencionada dificuldade de acesso a documentos internos quanto na postura da direção-geral, quando se realizou uma reunião para discutir os resultados parciais da pesquisa. Enquanto os trabalhadores e gestores concordaram com os dados e agregaram críticas construtivas, a diretoria mostrou-se reativa. Na ocasião, foram questionados alguns dados da pesquisa, refutadas algumas considerações provenientes do diário de campo, além de haver uma postura de justificativa dos dados relativos às dificuldades enfrentadas pela instituição concernentes à PNH. Chegou-se ao extremo de negar relatos de alguns sujeitos da pesquisa, propondo aprofundamentos, sugerindo modificar algumas percepções, o que demandou negociação firme, visando sustentar o delineamento e os objetivos do estudo.

\section{A efetivação da PNH nas práticas cotidianas}

Vale ressaltar que o hospital em questão se constituiu há tempos como importante equipamento de saúde em Belo Horizonte. É referência em várias especialidades e em atendimentos de urgência e emergência na capital mineira e cidades vizinhas, e, de modo geral, é considerado um serviço de saúde de qualidade. Não é nossa intenção desqualificar o serviço ou denegrir a construção da PNH realizada no estabelecimento de saúde, e sim evidenciar os hiatos, brechas e lacunas do processo como forma de contribuir para alavancar a experiência no hospital, pois acredita-se que não se ganha apenas apresentando resultados favoráveis ou positivos. É nessa perspectiva 
que se pretende empreender as análises desse serviço de saúde, no espaço entre as intenções e as efetivações.

A implantação de uma política é complexa e requer abordagens compatíveis com essa complexidade. É importante que se tenha claro no mínimo três noções: 1) não há mobilização sem implicação, carece-se de engajamento e interesse dos atores que se propõem a implantá-la para promover alterações e mudanças; 2) a política não se efetiva de forma homogênea e linear, seja nos diferentes serviços, seja nas diferentes instâncias de um mesmo equipamento de saúde; portanto, deve-se partir dos saberes e conhecimentos acumulados por quem se ocupa da práxis diária, reconhecendo as especificidades existentes em cada localidade; e 3) novos arranjos dependem amplamente dos trabalhadores para a sua funcionalidade, pois são nas ações cotidianas que se operam seus pressupostos e as mutações da realidade. Assim, é fundamental envolver os trabalhadores na construção dos planos.

Infere-se que a PNH, como descrita no documento base (Brasil, 2008), intenciona que sua implantação ocorra na perspectiva acima mencionada, porém ela não pode garantir que assim seja, posto que a determinação desse processo é dada por aqueles que promovem as ações em saúde, ou seja, os sujeitos que compartilham a vida institucional. Assim, procurou-se compreender como a $\mathrm{PNH}$ chega aos trabalhadores, como eles se apropriam de seu ideário e que reações ela provoca neles.

A primeira vertente que diz respeito à mobilização para se implantar a PNH fez-se por uma decisão do grupo gestor do complexo hospitalar, apoiado intensivamente pela consultoria do Ministério da Saúde, visando mudar o modelo de gestão. Tal decisão foi fundamental para incitar novos arranjos organizacionais no estabelecimento de saúde. E as ações concretas desenvolvidas por meio dos dispositivos, princípios e diretrizes do HumanizaSUS conseguiram produzir relevantes alterações na organização dos processos de trabalho, na gestão e no espaço físico, implicando novos manejos administrativos e financeiros.

A segunda vertente relativa à efetivação heterogênea e não linear da implantação da política refere-se à especificidade dela na instituição estudada. Houve apoio intensivo do Ministério da Saúde para tal, e a parceria da instituição com o Ministério da Saúde possibilitou forjar, com base na sua experimentação coletiva, novos arranjos que impactaram na formulação da $\mathrm{PNH}$, como indica o relato a seguir: "alguns dispositivos que a gente foi construindo e foi também discutindo com a Política Nacional e fomos implementando" (Agente da SMS). Tais arranjos foram disparadores tanto de novos movimentos quanto de novos impasses: "a gente construiu coletivamente as coisas. Às vezes, a gestora até falava: 'Eu quero assim', mas escapava dela, porque os movimentos eram muitos (...), [as decisões] eram validadas no colegiado gestor ampliado" (Consultor do Ministério da Saúde 2). 
Contudo, sendo a implantação de uma política um processo dinâmico e constante, no hospital em questão não se conseguiu manter a sensibilização, a mobilização e os efeitos iniciais provocados pela implantação da PNH com a mesma vitalidade e efetividade nos tempos atuais.

Essa constatação se relaciona com a terceira vertente, que diz respeito à necessidade de envolver constantemente quem vai operacionalizar os pressupostos abstratos da política - os trabalhadores -, pois sua funcionalidade dependerá amplamente deles. Nesse sentido, as alterações ocorridas encontraram dificuldades no percurso de implantação da nova organização gerencial e da PNH, e ainda hoje persistem, diferenciadas da fase de implantação, mas não menos contundentes. Foram implantadas no hospital as seguintes diretrizes e dispositivos: Cogestão - Colegiado Gestor e Contrato de Gestão; Clínica Ampliada - Equipe Transdisciplinar de Referência e Apoio Matricial; Acolhimento - Acolhimento com classificação de riscos; Ouvidoria, Posso ajudar?; Defesa dos Direitos dos Usuários - Visita Aberta, Direito a Acompanhante; Projeto Terapêutico Singular; Valorização do Trabalho e Trabalhador - Projetos de Ambiência (Araújo e Rates, 2009).

Não foi possível discutir, neste texto, os detalhamentos da implantação das diretrizes e dos dispositivos da PNH na instituição hospitalar, por causa da limitação na obtenção de dados e documentos para tal, como mencionado na parte metodológica. Portanto, privilegiou-se a análise da PNH em operação no ambiente hospitalar, por meio dos relatos dos trabalhadores e das observações realizadas no trabalho de campo.

Os colegiados gestores são espaços protegidos de participação e debate para a tomada de decisões coletivas, pautados pela diretriz da cogestão (Rates, 2009). No hospital, ocorrem colegiados das unidades de produção mensalmente, em dias e horários intercalados, a fim de possibilitar ampla participação dos trabalhadores. São dois tipos de colegiados: o colegiado das UPs é formado por trabalhadores, coordenadores e gerentes; já o Colegiado Gestor Ampliado é integrado pelos diretores, gerentes, referências técnicas e representantes dos trabalhadores de cada Unidade de Produção.

$\mathrm{O}$ documento base da PNH expressa que os colegiados gestores garantem o compartilhamento do poder, a coanálise, a codecisão e a coavaliação (Brasil, 2008). A prática revela que essa afirmação carrega certo grau de idealização, pois apenas o estabelecimento desse espaço não oferece garantias de que a democratização do poder ocorra, nem que os trabalhadores participem das tomadas de decisão. A baixa capacidade deliberativa deles revela-se como um elemento inibidor da participação, o que foi dito por vários trabalhadores e parcialmente reconhecido por uma das gestoras.

Participo quando dá, no colegiado pouca coisa se resolve, é uma enganação (Técnico Superior). 
O colegiado é mais para assuntos burocráticos, algo que você acha que está errado e precisa melhorar. Mas olha, dá uma canseira, tem que discutir muito, a coisa não anda na velocidade que precisa (Técnico Superior).

Tem que participar, a gente é cobrado por isso, mas, sinceramente, é uma embromação, muito lero-lero (Técnico Nível Médio).

A gente sensibiliza para o colegiado, chama para o colegiado, puxa pelo braço para ir para o colegiado (...). A gente tem reuniões colegiadas ainda muito tímidas, não por presença, mas por efetividade. Eles são tímidos ainda na hora de dizer, de falar as coisas, eles têm a impressão de penalidades posteriores, eles ainda têm medo de dizer aquilo que pode ser mudado no processo de trabalho, com medo de represália mesmo, mas é um processo (Gestora 2).

Se por parte dos trabalhadores um fator inibidor da participação ativa é a baixa capacidade deliberativa e de efetividade do espaço de decisão colegiada, por parte da gestão infere-se de que o espaço participativo diz respeito às relações de poder.

A descentralização do poder em espaços pretensamente democráticos pode estar a serviço do controle velado e da dominação. Carapinheiro (apud Cecílio e Mendes, 2004) elencou três modos de dominação para analisar o tipo de dominação exercida pelos médicos: subordinação, limitação e exclusão. Essa ideia pode ser aproximada aos tipos de dominações que podem ocorrer nos colegiados gestores. A subordinação de um saber a outro no colegiado pode ser revelada quando as propostas são descredenciadas ou desconsideradas; a dominação por limitação pode ocorrer quando há diminuição ou restrição dos domínios de ação de um sujeito ou coletivo, que podem aparecer nos colegiados sob a forma de boicote a determinada proposta ou quando as decisões não são mantidas ou legitimadas; por último, a dominação por exclusão pode se apresentar quando não se favorece a circulação da palavra, quando se promove o silenciamento dos sujeitos ou quando as demandas e necessidades dos trabalhadores nunca se realizam. Assim, entende-se que o controle se exerce por meio da dominação, e o fato de o órgão colegiado tornar-se mais consultivo do que deliberativo só reafirma essa relação, além de produzir nos integrantes um sentimento de não serem representados nesse espaço (Cecílio e Mendes, 2004).

Percebeu-se na investigação não apenas que a perspectiva da gestão destoa bastante da perspectiva dos trabalhadores, mas também que há marcadas diferenças entre trabalhadores de nível médio e de nível superior, o que permite afirmar que o aumento comunicacional, propiciado pelos espaços de participação, não é, necessariamente, acompanhado do aumento na qualidade dessa comunicação, impossibilitando a interseção entre a verticalidade 
e a horizontalidade das hierarquias (Guattari, 1987), de modo a integrar as perspectivas e promover a transversalidade proposta pela $\mathrm{PNH}$.

De certo modo, os técnicos de nível médio, menos assessorados e menos assistidos, percebem com maior clareza do que os técnicos de nível superior a segmentação de procedimentos e a hierarquia fortemente demarcada em temas como o trabalho em equipe. Dos técnicos de nível médio, nessa e em outras ocasiões, provêm as críticas mais duras à implantação da $\mathrm{PNH}$, quando avaliam a transversalização do trabalho multiprofissional. “Tem um querendo mandar mais que o outro" (Técnico Nível Médio). "Sinto falta de suporte, a gente trabalha junto, mas não acho que seja equipe mesmo. Acho que equipe é para se ajudar, se apoiar, se cada um faz o seu, não sei, não" (Técnico Nível Médio).

Já o ponto de vista dos técnicos de nível superior sobre o mesmo tema é, em geral, bem mais auspicioso: "A equipe é boa, as pessoas trocam experiências, tiram dúvidas, ensinam e aprendem, responsabilizam-se pelos casos" (Técnico Superior de Saúde).

A análise de Cecílio e Mendes sobre o processo de gestão em um hospital público e o protagonismo dos trabalhadores também auxilia na compreensão dessa situação:

O cotidiano do hospital encontra-se atravessado por regras formais e informais que, todo o tempo, influenciam e modificam o projeto de gestão da atual administração. Os novos dispositivos não conseguem ser implementados plenamente no dia a dia do hospital, pois a lógica da direção estabelece-se como apenas uma das lógicas que irão influenciar na definição das ações realizadas pelas profissionais de saúde (Cecílio e Mendes, 2004, p. 49).

As distintas posições hierárquicas (gestores, consultoria, trabalhadores de nível superior e trabalhadores de nível médio) demonstraram uma compreensão parcial e heterogênea sobre a eficácia e os efeitos dessa política. Acredita-se que as divergências aconteçam tanto pela distinção das capacitações ofertadas aos servidores do hospital, variando conforme sua ocupação hierárquica na instituição, quanto pela pouca consistência no desenvolvimento da autoanálise e da autogestão pelos trabalhadores, o que dificulta posicionamentos mais críticos e transformadores, mantendo-se os mesmos no nível das alterações organizacionais.

A formação dos apoiadores em gestão hospitalar teve como público-alvo os gerentes, coordenadores e supervisores, contando com outros convidados, consultores do Ministério da Saúde e professores. Ao focar o grupo gerencial e capacitando-o teórica e praticamente, acreditou-se que as propostas da $\mathrm{PNH}$ podiam ser potencializadas e disseminadas a todos os profissionais em atuação direta com o usuário, na assistência, na rotina de trabalho, pela transmissão de conhecimentos adquiridos pelas suas chefias, conforme relato: 
Nós temos gerentes coordenadores muito heterogêneos, aqueles que são absolutamente inseridos na clínica ampliada e aqueles que ainda não conhecem o projeto terapêutico singular foram fazer oficinas mensais durante todo o ano que passou, focadas no desenvolvimento dos dispositivos de uma forma uniforme para todos, porque não adianta desenvolver os funcionários se os gestores não conhecem aquilo que o funcionário está trazendo, o que ele está cobrando. Então identificamos que, trabalhando os gestores e coordenadores primeiramente, teríamos um resultado melhor com o técnico. Porque nós nivelamos os gerentes e coordenadores na mesma metodologia, nos mesmos dispositivos, para que eles fossem capazes de fazer isso chegar na ponta. (...) mesmo que aquele técnico não tenha vindo para a sala de aula e tenha recebido a mesma informação que o gestor, isso está funcionando na prática, porque o gestor vai chamá-lo à responsabilidade de fazer parte da mudança (Gestora 2).

Os trabalhadores também têm acesso às capacitações, porém seus conteúdos são muito diferentes. A maioria delas consiste em instrumentalizações técnicas que variam conforme a especificidade do trabalho, a unidade de lotação e a formação profissional. Questões acerca da PNH são muito incipientes. Efeitos disso transparecem inclusive em reclamações como esta: "Que humanização é essa, só para o usuário? O funcionário também precisa de humanização" (Técnico Nível Médio). Alguns técnicos superiores também demonstraram pouca apreensão do sentido da humanização preconizada pela política: "Não sei falar muito disso [dispositivo ou diretriz] para você, pergunta para a (...) [supervisora de UP], que ela pode responder melhor" (Técnico Superior de Saúde).

São os trabalhadores que, em última instância, colocam em ação, em prática, a PNH. São eles que a tornam funcional. Não havendo uma compreensão adequada de seus pressupostos, os dispositivos, que são os operadores deles, ficam restritos ao arranjo técnico e não transformam a realidade, mas mantêm a lógica vigente, revestida com uma roupagem mais glamourosa.

A distinção expressiva das capacitações ofertadas aos gestores e trabalhadores caminhou na contramão das pretensões da PNH. A compartimentagem dos conhecimentos promove uma dicotomia entre quem pensa e quem executa, causando a alienação, e desfavorece o desenvolvimento da autonomia e protagonismo, um dos princípios dessa política. “A alienação real dos trabalhadores é, portanto, a separação, concreta e cotidiana, dos produtores da gestão, dos meios de produção e do resultado de seu próprio trabalho" (Campos, 2000, p. 27).

A alienação a que são submetidos os trabalhadores os incapacita, muitas vezes, para perceberem a PNH operando. Porém, não os afeta a ponto de se tornarem protagonistas de mudanças, porque não se alterou profundamente a lógica de reprodução e dominação. Como resultado, tem-se a descrença na 
efetividade da atuação da política e seu descredenciamento, dificultando que seja feito o investimento necessário para a sua consolidação.

A compreensão de muitos trabalhadores sobre a ineficiência da PNH é atribuída, pelas gestoras, à substituição da maioria dos profissionais envolvidos com a implantação do HumanizaSUS a partir do ano de 2003. Esses se vinculavam à instituição, há muitos anos, por contratos administrativos. Com a realização de concursos públicos, efetuados a partir do ano de 2006 e nos anos seguintes, ocorreu uma substituição maciça de profissionais contratados por servidores efetivos. O quadro de funcionários do hospital até 2008 constava de 2.189 profissionais distribuídos entre as diversas categorias e níveis de estudo. Somente no concurso do ano de 2006, contabilizaram-se mais 919 vagas disponíveis, conforme edital n. 001/2006 (Belo Horizonte, 2006), por exigência do Ministério Público de criar cargos públicos efetivos, em substituição aos contratos administrativos. Outra justificativa dada pelas gestoras é a insuficiência da manutenção da mobilização a longo prazo, após o primeiro esforço de implantação, com a criação de oficinas e rodas de conversa, quando o apoio do Ministério da Saúde foi mais intenso.

A partir das auditorias, identificamos que muito do que a gente implantou se perdeu, muito do que a gente trabalhou com eles nas oficinas se perdeu. E se perdeu porque se perderam os funcionários, a manutenção se perdeu, porque implantar uma cultura é igual a uma planta, que você planta, rega e ela cresce. Tem de fazer manutenções, tem de fazer as oficinas, tem de fazer troca de experiência, você tem de manter aquilo vivo dentro do funcionário, e essa manutenção nós não conseguimos fazer, porque trocamos muitos dos funcionários do período em que a gente implantou [a política] até agora (Gestora 2).

Entretanto, muitos funcionários que estavam ativos no hospital nessa época, variando de seis a 17 anos no serviço, demonstraram similar apreensão em relação aos preceitos e efeitos da PNH. Há uma baixa efetividade dos dispositivos e diretrizes, um conhecimento incipiente deles ou uma compreensão equivocada de que a política centra-se na qualidade da assistência voltada apenas para o usuário. Portanto, não é possível jogar sobre a substituição de profissionais a razão final dos impasses atuais.

Um terceiro elemento que surge como dificultador foram as próprias condições do trabalho, com a urgência e emergência hospitalares. Especialmente os profissionais que trabalham no pronto-socorro acentuaram a tensão entre realização do acolhimento e pressões relativas ao trabalho e metas de produção determinadas pelos critérios do Protocolo de Manchester. Cada atendimento no acolhimento com classificação de risco leva em torno de dois minutos. 
O acolhimento que temos aqui é mais [visando à] tradução das queixas e o trabalho pedagógico, porque você vê o hospital lotado e não dá para ficar escutando muito: há muita pressão para o atendimento rápido, os protocolos são auditados, temos metas (Técnico Superior de Saúde).

Faço o possível para acolher o usuário, mas o serviço de urgência impõe limitação para isso; é complicado (Técnico Superior de Saúde).

Houve casos em que a pressão da rotina de trabalho foi um fator impeditivo de maior envolvimento dos trabalhadores nas atividades ligadas à PNH. Assim avalia um trabalhador: "Ah, aconteceram mesmo [atividades para implantação da $\mathrm{PNH}]$, teve muita pressão para que a gente participasse de oficinas, de reuniões, mas o trabalho não para, quem fica aqui se todo mundo sai?" (Técnico Superior de Saúde).

Entende-se que o HumanizaSUS pode ser efetivo se as ações conduzidas em seu nome estiverem influenciadas por seus princípios norteadores. Por efetividade, entende-se menos a implantação de dispositivos da PNH e sim a instauração de mudanças significativas nos modos de gerir e cuidar que consigam avançar em direção à autonomia, ao protagonismo, às relações solidárias, às pactuações responsáveis e compromissadas, ao respeito da singularidade alheia e ao enfrentamento do corporativismo, questões significativas para o SUS. Não há possibilidade de se obter uma melhor qualidade da assistência se não for construída uma adequada gestão do trabalho em saúde (Brasil, 2008). Obviamente, como processo dinâmico, flexível e mutável, dificilmente a PNH atingirá a completude de seus pressupostos, que se constituem como uma utopia. Porém, se os dispositivos em ação que embasam as práticas e os arranjos não se deixam permear por tais princípios, haverá alterações e algum impacto, no entanto, esses permanecerão no nível superficial, sem modificar radicalmente os sujeitos e as práticas.

\section{Considerações finais}

É importante ressaltar que houve dificuldades no percurso das alterações ocorridas no hospital, a partir da implantação da $\mathrm{PNH}$, que ainda hoje persistem. Conclui-se que, no hospital estudado, houve dois momentos distintos do HumanizaSUS: o primeiro, na fase de implantação, quando ocorreu um processo intenso de participação dos servidores nas rodas, oficinas e colegiados, bastante potente para introduzir as alterações que ocorreram. Esse esforço não se sustentou a médio prazo, seja em virtude dos concursos públicos, que levaram à substituição de grande parte dos trabalhadores, 
seja por causa do afrouxamento na transformação da cultura institucional ou, ainda, em decorrência das vicissitudes próprias do trabalho hospitalar. Um segundo momento se iniciou com o distanciamento do apoio institucional que auxiliava a catalisação de recursos, a mobilização e o planejamento das ações, muitas vezes assumindo essas tarefas. Com isso, houve certa desvitalização dos pressupostos da PNH e um baixo investimento em recuperar a mobilização. Além disso, alguns processos não foram retomados, ocasionando a descrença dos servidores da instituição quanto à sua eficiência, o que indica não ter se mantido a autossustentabilidade após o final da parceria mais intensa com o Ministério da Saúde.

Acreditamos que a PNH é de fato uma utopia com possibilidades de concretização, dependendo de como for implantada. Apresenta inovação em relação às práticas do setor privado ao visar superar um modelo de humanização centrado na 'satisfação do cliente', associando as práticas de cuidado às de gestão. É uma política de enfrentamento de uma lógica contemporânea pautada em relações de consumo e que trata a saúde como mercadoria, como produto. Entendemos que o maior desafio é transpor essa lógica e instaurar uma nova forma de se relacionar e atuar na saúde. Para que isso ocorra, é necessário intervir sobre a totalidade da conjuntura institucional onde a política está sendo implantada, o que não é uma tarefa qualquer.

\section{Colaboradores}

Os autores participaram igualmente da produção e revisão do texto. 
Resumen El artículo analiza la experiencia de implantación de la Política Nacional de Humanización en una institución hospitalaria pública de Belo Horizonte, Minas Gerais, Brasil. El estudio se concentra en los avances y límites de la gestión participativa propuesta por la política de humanización en el escenario hospitalario. Se trata de un enfoque cualitativo, por medio de un estudio de caso en el cual se utiliza investigación documental, entrevistas y observación. Los datos se trataron mediante análisis temático de contenido, construyendo categorías temáticas desde una perspectiva de la historia del proceso de implantación de la Política Nacional de Humanización. El esfuerzo de la fase de implantación y el apoyo del Ministerio de la Salud no se sustentaron a medio y largo plazo en el hospital. La Política Nacional de Humanización innova con relación a las prácticas del sector privado, al superar un modelo de humanización centrado en la 'satisfacción del cliente', asociando las prácticas de cuidado a las de gestión. No obstante, el mayor desafío es transponer esta lógica e instaurar una nueva forma de relacionarse y de actuar en la salud. Para que ello ocurra, hay que intervenir sobre la totalidad de la coyuntura institucional.

Palabras clave política de salud; Política Nacional de Humanización; proceso de trabajo; gestión participativa.

\section{Notas}

1 Prefeitura Municipal de Nova Lima, Minas Gerais, Brasil.

Mestre em Psicologia pela Pontifícia Universidade Católica de Minas Gerais.

<alessandra_bpereira@yahoo.com.br; alessandrabpereira@gmail.com>

Correspondência: Rua Augusto Moreira, n. 322, Santa Amélia, CEP 31555-100, Belo Horizonte, Minas Gerais, Brasil.

2 Pontifícia Universidade Católica de Minas Gerais, Belo Horizonte, Minas Gerais, Brasil.

Pós-doutor em Psicologia Social pela Universidade do Estado do Rio de Janeiro e doutor em Psicologia Clínica pela Pontifícia Universidade Católica de São Paulo.

<jleitefn@gmail.com; jleite.bhe@terra.com.br> 


\section{Referências}

ARAÚJO, Gilvan F.; RATES, Suzana M. M. (Org.). Cogestão e humanização na saúde pública: experiências construídas no Hospital Municipal Odilon Behrens. 2. ed. rev. e ampl. Ijuí: Editora Unijuí, 2009.

BELO HORIZONTE. Prefeitura Municipal de Belo Horizonte. Edital do concurso público 01/2006. Belo Horizonte: Prefeitura Municipal de Belo Horizonte, 2006.

BENEVIDES, Regina; PASSOS, Eduardo. Humanização na saúde: um novo modismo? Interface: Comunicação, Saúde, Educação, Botucatu, v. 9, n. 17, p. 389-406, 2005.

BRASIL. Ministério da Saúde. Oficina Nacional HumanizaSUS: construindo a Política Nacional de Humanização. Brasília: Ministério da Saúde, 2003a.

BRASIL. Ministério da Saúde. Conselho Nacional de Saúde. CONFERÊNCIA NACIONAL DE SAÚDE, 11. Efetivando o SUS: acesso, qualidade e humanização na atenção à saúde com controle social. Relatório final. Brasília: Ministério da Saúde, 2003b. (Série D: Reuniões e conferências).

BRASIL. Ministério da Saúde. Secretaria de Atenção à Saúde. Núcleo Técnico da Política Nacional de Humanização. HumanizaSUS: documento base para gestores e trabalhadores do SUS. 4. ed. Brasília: Ministério da Saúde, 2008.

BRASIL. Ministério da Saúde. Secretaria de Atenção à Saúde. Política Nacional de Humanização da Atenção e Gestão do SUS. Gestão participativa e cogestão. Brasília: Ministério da Saúde, 2009.

CAMPOS, Gastão W. S. Um método para análise e cogestão de coletivos: a constituição do sujeito, a produção de valor de uso e a democracia nas instituições - o método da roda. São Paulo: Hucitec, 2000.
CAMPOS, Gastão W. S. Considerações sobre a arte e a ciência da mudança - revolução das coisas e reforma das pessoas: o caso da saúde. In: CECÍLIO, Luiz C. O. (Org.). Inventando a mudança na saúde. 3. ed. São Paulo: Hucitec, 2006. p. 29-88.

CAMPOS, Gastão W. S.; RATES, Suzana M. M. Segredos e impasses na gestão de um hospital público. In: ARAÚJO, Gilvan F.; RATES, Suzana M. M. (Org.). Cogestão e humanização na saúde pública: experiências construídas no Hospital Municipal Odilon Behrens. 2. ed. rev. ampl. Ijuí: Editora Unijuí, 2009. p. 45-51.

CECÍLIO, Luiz C. O.; MENDES, Taniella C. Propostas alternativas de gestão hospitalar e o protagonismo dos trabalhadores: por que as coisas nem sempre acontecem como os dirigentes desejam? Saúde e Sociedade, São Paulo, v. 13, n. 2, p. 39-55, 2004.

DEMO, Pedro Participação é conquista: noções de política social participativa. 6. ed. São Paulo: Cortez, 2009.

DESLANDES, Suely F. O projeto ético-político da humanização: conceitos, métodos e identidade. Interface: Comunicação, Saúde, Educação, Botucatu, v. 9, n. 17, p. 389-406, 2005.

FERREIRA NETO, João L. Psicologia, politicas públicas e o SUS. São Paulo: Escuta; Belo Horizonte: Fapemig, 2011.

GUATTARI, Félix. Revolução molecular: pulsações políticas do desejo. 3. ed. São Paulo: Brasiliense, 1987.

PASCHE, Dário F. Política Nacional de Humanização como aposta na produção coletiva de mudanças nos modos de gerir e cuidar. Interface: Comunicação, Saúde, Educação, Botucatu, v. 13, sup. 1, p. 701-708, 2009. 
PASSOS, Eduardo (Org.). Formação de apoiadores para a Política Nacional de Humanização da gestão e da atenção à saúde. Rio de Janeiro: Fiocruz, 2006. v. 2.

POPE, Catherine; ZIEBLAND, Sue; MAYS, Nicholas. Analisando dados qualitativos. In: POPE, Catherine; MAYS, Nicholas (Org.). Pesquisa qualitativa na atenção à saúde. 3. ed. Porto Alegre: Artmed, 2009. p. 77-95.

RATES, Suzana M. M. Unidades de Produção como espaço de construção democrática. In: ARAÚJO, Gilvan F.; RATES, Suzana M. M. (Org.). Cogestão e humanização na saúde pública: experiências construídas no Hospital Municipal Odilon Behrens. 2. ed. rev. ampl. Ijuí: Editora Unijuí, 2009. p. 53-63.

REIS, Alberto O. A.; MARAZINA, Isabel V.; GALLO, Paulo R. A humanização na saúde como instância libertadora. Saúde e Sociedade, São Paulo, v. 13, n. 3, p. 36-43, 2004.

RIVERA, Francisco J. U. A gestão situacional (em saúde) e a organização comunicante. Cadernos de Saúde Pública, Rio de Janeiro, v. 12, n. 3, p. 357-372, 1996.

SPINK, Peter K. A inovação na perspectiva dos inovadores. In: CONGRESO INTERNACIONAL DEL CENTRO LATINOAMERICANO DE ADMINISTRACIÓN PARA EL DESARROLLO SOBRE REFORMA DEL ESTADO Y DE LA ADMINISTRACIÓN PÚBLICA, 9. Anales... Madri: CLAD, 2 a 5 de novembro de 2004. Disponível em: <www. plataformademocratica.org/Publicacoes/ 3391_Cached.pdf>. Acesso em: 7 abr. 2014.
STRALEN, Cornelis J. V. Do Projeto Montes Claros para o Sistema Único de Saúde: o hiato entre a ideologia e as realizações práticas. In: TEIXEIRA, Sonia M. F (Org.). Projeto Montes Claros: a utopia revisitada. Rio de Janeiro: Abrasco, 1995. p. 165-191.

STRALEN, Cornelis J. V. Comentários em exame de qualificação. Programa de Pós-graduação stricto sensu em Psicologia da PUC-Minas. PUC-Minas: Belo Horizonte, 2010.

TRAJANO, Ana R. HumanizaSUS: um alerta contra a violência contemporânea? In: MELO, Elza Machado (Org.). Podemos prevenir a violência. Brasília: Opas, 2010. p. 107-120. (Série Promoção de Saúde e Prevenção da Violência).

TURATO, Egberto R. Tratado de metodologia da pesquisa clínico-qualitativa: construção teórico-epistemológica, discussão comparada e aplicação nas áreas da saúde e humanas. Petrópolis: Vozes, 2003.

Recebido em 08/05/2013

Aprovado em 05/12/2013 
